\title{
AS SECRETARIAS REGIONAIS E AS DIVISÕES CIENTÍFICAS DA SOCIEDADE BRASILEIRA DE QUÍMICA
}

\author{
Celso Camilo Moro \\ Instituto de Química, Universidade Federal do Rio Grande do Sul, CP 15003, 91501-970 Porto Alegre - RS, Brasil \\ Norberto Peporine Lopes* \\ Departamento de Física e Química, Faculdade de Ciências Farmacêuticas de Ribeirão Preto, Universidade de São Paulo, Av. do \\ Café, s/n, 14040-903 Ribeirão Preto - SP, Brasil \\ Romeu C. Rocha-Filho \\ Departamento de Química, Universidade Federal de São Carlos, CP 676, 13560-970 São Carlos - SP, Brasil
}

\begin{abstract}
THE REGIONAL SECRETARIES AND THE SCIENTIFIC DIVISIONS OF THE SOCIEDADE BRASILEIRA DE QUÍMICA. This article offers an overview on the historical facts and the recent state of the Regional Secretaries and the Scientific Divisions in the course of 30 years of SBQ.
\end{abstract}

Keywords: Regional Secretaries; Scientific Divisions; SBQ.

\section{INTRODUÇÃO}

A história do nascimento da SBQ está diretamente relacionada com a reconquista da democracia, tendo nossa sociedade nascido em 1977 em um ambiente truculento devido ao regime militar. Para os mais jovens que não conhecem essas passagens recomendamos a leitura dos artigos de Química Nova organizados na edição especial de maio de $2004^{1-3}$.

Logo no primeiro ano foram criados o Estatuto da SBQ e a revista Química Nova, sendo estas ações seguidas pela organização das primeiras secretarias regionais de Porto Alegre, Florianópolis, Maringá, Campinas, São Carlos-Ribeirão PretoAraraquara, Rio de Janeiro, Belo Horizonte, Viçosa, Salvador, Recife, Fortaleza e Brasília. Por outro lado, as divisões científicas nasceram apenas no início da década de 90, como uma nova etapa de organização da SBQ.

Atualmente a SBQ possui diferentes ações e estratégias de organização, inserção e participação na ciência brasileira. Nesse texto estaremos discutindo a criação e desenvolvimentos das secretarias regionais e das divisões científicas bem como as perspectivas futuras para essa estrutura.

\section{AS SECRETARIAS REGIONAIS}

Como comentado inicialmente, as secretarias regionais, de certa maneira já existiam no primeiro estatuto da SBQ, mas previstas como divisões estaduais.

\section{“CAPÍTULO VII - Das Divisões Estaduais}

Art. I - A Sociedade Brasileira de Química, poderá exercer suas atividades através de Divisões Estaduais, de acordo com deliberação do Conselho e da Diretoria, que apontarão, quando necessário, um representante em cada Estado que deverá ser escolhido de acordo com suas qualificações científicas e plano de trabalho."

Como se pode ver pela citação no Estatuto, a idéia era ter um representante em cada Estado, não necessariamente uma secreta-

*e-mail: npelopes@sbq.org.br ria, o que mais tarde foi reestruturado. Desde o início, no entanto, a denominação "divisão estadual" foi substituído pela de "secretaria regional", sendo as mesmas organizadas em regiões onde havia uma grande concentração de cursos superiores de Química. A primeira regional criada foi a de Araraquara-Ribeirão Preto-São Carlos, em junho de 1979, dirigida na ocasião pelo Prof. Romeu Cardozo Rocha Filho, da UFSCar. Mais tarde, na prática, diversos Estados tiveram mais do que uma regional, por exemplo: São Paulo (três regionais), Paraná (três regionais), Minas Gerais (três regionais). No Paraná, posteriormente houve a fusão das três regionais (Curitiba, Londrina e Maringá), mas Minas Gerais manteve duas regionais (Belo Horizonte e Viçosa) e São Paulo continua com três (Campinas, Araraquara-Riberião Preto-São Carlos e a sede nacional que atua também como a Regional de São Paulo).

No início da década de 90 a SBQ passou por uma reestruturação e novas normas sobre as secretarias regionais foram redigidas e nessa mesma época foi feita a regulamentação das divisões científicas. Todas as propostas foram submetidas à assembléia geral da SBQ e foram aprovadas durante a $16^{\mathrm{a}}$ Reunião Anual, em maio de 1994, após revisão por secretários regionais. O texto completo das normas das Secretarias Regionais pode ser obtido acessando-se o sítio http://www.sbq.org.br/portal2/secRegionais/normassec.htm. Destacamos abaixo os itens principais dessas normas.

\section{Da criação de uma Secretaria Regional}

Um grupo de sócios deve submeter à Diretoria e ao Conselho da SBQ o pedido de criação de uma Secretaria Regional. Nesta solicitação devem ser incluídos os seguintes aspectos que constituirão a exposição de motivos:

i. área de abrangência geográfica da Secretaria Regional;

ii. relação de sócios residentes na área geográfica abrangida, por categoria e que estejam filiados à SBQ pelo menos há um ano;

iii. descrição das atividades em Química que se desenvolvem na região e de como a presença de uma Secretaria Regional da SBQ poderia incrementá-las ou melhorá-las;

iv. programa de atividades que serão desenvolvidas nos primeiros dois anos de sua implantação. 


\section{Das finalidades}

Uma Secretaria Regional tem por finalidade congregar os sócios da SBQ de uma dada região, realizar atividades que levem à consecução das finalidades da SBQ e a uma melhor comunicação com a Diretoria da SBQ, bem como promover a imagem da SBQ na região e arregimentar novos sócios.

A Diretoria Regional será eleita bienalmente pelos sócios efetivos da Secretaria Regional, dentre seus pares, e será composta de um Secretário, um Vice-Secretário e um Tesoureiro. O mandato da Diretoria Regional coincidirá com o da Diretoria da SBQ.

5. Compete à Diretoria Regional:

i. representar a SBQ frente aos sócios da Secretaria Regional;

ii. executar as deliberações da Assembléia Geral Regional;

iii. elaborar o orçamento anual, arrecadar as anuidades e elaborar, anualmente, relatório financeiro;

iv. programar e executar as atividades anuais da Secretaria Regional, bem como elaborar o relatório anual de atividades;

v. convocar extraordinariamente a Assembléia Geral Regional;

vi. submeter cópia da ata de Assembléia Geral Regional à Diretoria da SBQ, a qual notificará a Assembléia Geral sobre o recebimento do mesma;

vii. organizar a eleição de nova Diretoria Regional e designar sócios efetivos para apurá-la;

viii. fixar a data para a Assembléia Geral Regional ordinária;

ix. prestar contas ou esclarecimentos à Diretoria da SBQ, caso solicitado.

6. Compete ao Secretário Regional:

i. representar a Secretaria Regional junto à SBQ;

ii. presidir as reuniões da Diretoria Regional e da Assembléia Geral Regional;

7. Compete ao Vice-Secretário Regional:

i. substituir o Secretário Geral em seus impedimentos;

ii. secretariar as reuniões da Diretoria Regional e da Assembléia Geral Regional.

8. Compete ao Tesoureiro Regional:

i. arrecadar as anuidades dos sócios e outras contribuições;

ii. administrar o patrimônio da Secretaria Regional de acordo com normas baixadas pela Diretoria Regional.

9. A Assembléia Geral Regional, órgão soberano da Secretaria Regional, será integrada por todos os sócios efetivos quites e reunir-se-á obrigatoriamente uma vez por ano, em data marcada pela Diretoria Regional (com quinze dias de antecedência), previamente à Assembléia Geral ordinária da SBQ, a fim de julgar os relatórios de atividades e financeiro apresentados pela Diretoria Regional, e em sessão extraordinária convocada pela Diretoria Regional ou por maioria simples dos sócios efetivos quites com as obrigações com a SBQ.

\section{Da extinção ou modificação de uma Secretaria Regional}

1. A Secretaria Regional poderá ser extinta, a qualquer tempo:

i. por deliberação absoluta dos sócios em Assembléia Geral Regional especialmente convocada para este fim;

ii. por deliberação da Diretoria da SBQ, ouvido o Conselho, constatada a patente inatividade da Secretaria Regional ou o reincidente descumprimento destas Normas. iii. Em caso de extinção, a administração do patrimônio social e fundo de reserva da Secretaria Regional será transferida para a Tesouraria da SBQ.

2. A Secretaria Regional poderá ser modificada quanto à sua abrangência geográfica, por decisão da Assembléia Geral Regional especialmente convocada para este fim, após o de acordo da Diretoria da SBQ, ouvido o Conselho.

A principal função de uma secretaria regional é manter o contato entre os associados da SBQ localizados nas diferentes regiões e ao mesmo tempo congregar idéias e iniciativas para o desenvolvimento mais uniforme da Química no Brasil. Esse objetivo pode-se dizer foi alcançado com grande eficiência, pois, indiretamente, graças à SBQ (reuniões anuais e encontros regionais, revistas científica com pareceres por pares, participação em programas de órgãos de fomentos - ProQuim, PADCT e outros) houve uma melhoria na qualidade dos cursos de Química em todo o Brasil e mais recentemente a proliferação de cursos de pós-graduação.

As formas encontradas pelas regionais de congregar os associados da SBQ da sua região foram bem diversas. Umas optaram pela realização de cursos de curta duração, tentando atingir alunos de graduação e Ensino Médio na área técnico-científica, buscando aprimorar o ensino tradicional. Outras se dedicaram a incentivar o ensino de Química nos diversos graus (médio e superior), organizando encontros onde eram dados subsídios aos professores de Química, principalmente aos recém-egressos dos cursos de graduação, que se dedicavam ao Ensino Médio. Em algumas regionais, desde os primeiros anos de sua criação, se realizam encontros regionais de Química. Nesses encontros, organizados nos moldes da Reunião Anual da SBQ, se discute as políticas do ensino de Química, da pesquisa e da extensão na região, bem como se incentiva aos alunos de iniciação científica e aos pós-graduandos a apresentarem seus trabalhos científicos.

No entanto, com o tempo começou a haver um desgaste nas relações entre a sede nacional e as regionais, fruto talvez do grande crescimento da nossa sociedade tanto em número de associados como em atividades, e continuando o mesmo número de pessoas a realizar todas as tarefas. Tentando dar mais atenção às atividades das regionais, foi designado o primeiro secretário como responsável pelas regionais.

Buscando melhorar as relações entre a diretoria e as regionais foi realizado em 2003 o $1^{\circ}$ Workshop das Secretarias Regionais da SBQ, onde foram discutidos os problemas de cada regional e apresentadas sugestões para a solução dos mesmos. Em 2005 foi realizado um segundo workshop, do qual saiu a "Carta de Poços de Caldas", na qual os secretários regionais apresentaram os principais problemas e uma série de reivindicações à Diretoria e ao Conselho da SBQ, podendo-se destacar: a falta de comunicação entre as Secretarias Regionais e a Secretaria Nacional e, às vezes, a lenta resposta das solicitações; a falta de repasses automáticos das cotas financeiras de cada regional; o problema da demora na transferência da titularidade das Secretarias quando da troca de secretários. Também foi citado como problema a dificuldade de acesso ao sítio gerencial de informática da SBQ, no qual são mantidos os dados dos respectivos associados.

Nesses dois workshops foi constatado que em várias secretarias regionais não houve crescimento do número de associados, e até que, em alguns casos, houve diminuição desse número, sendo que em alguns Estados não houve sequer interesse em eleger nova diretoria.

A Tabela 1 mostra o quadro atual das secretarias regionais existentes. Algumas dessas foram implantadas numa determinada época, porém por várias razões acabaram se tornando inativas. Mesmo tendo associados na região, não há secretário regional e, desta forma, as reivindicações dos mesmos são remetidas diretamente à Secretaria Nacional. 
Tabela 1. Situação atual das regionais da SBQ

\begin{tabular}{lcc}
\hline $\begin{array}{l}\text { Secretaria } \\
\text { Regional }\end{array}$ & $\begin{array}{c}N^{\circ} \text { de Sócios Efetivos } \\
\text { (março de 2007) }\end{array}$ & $\begin{array}{c}\text { Secretário } \\
\text { Regional }\end{array}$ \\
\hline Acre & 1 & Inativa \\
Alagoas & 30 & Adriana S. Ribeiro \\
Amazonas & 18 & Inativa \\
I. Paulista & 338 & Quézia Bezzera Cass \\
Bahia & 83 & Mauro Korn \\
Belo Horizonte & 166 & Ruth H. U. Borges \\
Brasília & 50 & Alexandre G. S. do Prado \\
Campinas & 182 & Claudia Longo \\
Ceará & 34 & Otília D. Loiola Pessoa \\
Espírito Santo & 17 & inativa \\
Goiás & 36 & Liliane Magalhães Nunes \\
Juiz de Fora & 20 & SR de Belo Horizonte \\
Londrina & 33 & SR do Paraná \\
Maranhão & 15 & Ridvan Nunes Fernandes \\
Maringá & 27 & SR do Paraná \\
Mato Grosso & 7 & Paulo T. de Souza Jr. \\
Mato G do Sul & 26 & inativa \\
Pará & 20 & inativa \\
Paraíba & 30 & Mário L. A. Vasconcelos \\
Paraná & 86 & Paulo R. Pinto Rodrigues \\
Pernambuco & 39 & Severino Alves Jr. \\
Piauí & 21 & Carla V. R. de Moura \\
Rio de Janeiro & 303 & Carlos Magno Rocha Ribeiro \\
Rio G do Norte & 10 & Everlane Ferreira Moura \\
Rio G do Sul & 158 & Hugo T. S. Braibante \\
Rondônia & 2 & inativa \\
Roraima & 7 & Robson F. de Farias \\
Santa Catarina & 89 & Iolanda da Cruz Vieira \\
São Paulo & 341 & Sem Secretário Regional \\
Sergipe & 26 & José do Patrocínio Alves \\
Tocantins & 1 & inativa \\
Viçosa & Cláudio Ferreira Lima \\
\hline & 24 &
\end{tabular}

Em face do apresentado, cumpre discutir agora, no momento em que se está elaborando um novo Estatuto para a SBQ, uma nova estruturação das Secretarias Regionais. Deve-se considerar que as possibilidades de comunicação entre e com os associados, depois do advento da Internet e da criação do Boletim Eletrônico da SBQ, mudaram completamente e, portanto, a congregação de todos se torna mais fácil, inclusive com a realização de eleições eletrônicas. Por outro lado ainda permanece a necessidade de se estabelecer um núcleo da SBQ em todos os cantos do País, respeitando as particularidades de cada Região e procurando atender as necessidades das mesmas.

Como serão as novas secretarias regionais? É hora da comunidade se manifestar, mostrar o que é necessário e possível de ser feito, para que a SBQ continue crescendo e, ao mesmo tempo, solidificando suas bases.

\section{AS DIVISÕES CIENTÍFICAS}

A história das secretarias regionais remonta aos períodos iniciais da SBQ, contudo as divisões científicas surgiram após a saída da SBQ da reunião anual da SBPC. No início de 1990, os químicos passaram a reivindicar um maior espaço para discussões mais específicas. Apesar de vários colegas estimularem a criação de divisões em períodos anteriores à saída da reunião da SBPC, apenas em 1994 as divisões foram oficialmente criadas. No biênio 19921994, alguns colegas trabalharam ativamente na criação das divi- sões científicas, tendo sido organizados os primeiros desenhos de seu funcionamento, como foi noticiado no Boletim Informativo da $S B Q$ de junho de 1994. Nessa gestão, em 28 de maio de 1994, a diretoria, ouvido o conselho consultivo e diretores das divisões já existentes (e algumas em organização), atendendo ao disposto no item j do artigo 3 do capítulo VI dos Estatutos da Sociedade Brasileira de Química, aprovou as Normas sobre Divisões Científicas. Seguindo a mesma sistemática anterior destacamos abaixo os principais itens desse documento, que se encontra no sítio http:// www.sbq.org.br/portal2/divisoes/divnormas.htm.

\section{Da criação de uma Divisão Científica}

1. Um grupo de sócios deve submeter à Diretoria e ao Conselho Consultivo da SBQ o pedido de criação de uma Divisão Científica. Nesta solicitação devem ser incluídos os seguintes aspectos que constituirão a exposição de motivos:

i) sub-área da Química abrangida pela Divisão Científica;

ii) programa de atividades que serão desenvolvidas nos primeiros dois anos de sua implantação.

2. Apreciados estes aspectos, cabe à Diretoria e ao Conselho Consultivo, ouvidas as Diretorias das Divisões Científicas já constituídas, aprovar ou não a criação da nova Divisão Científica.

3. Caso a proposta de criação seja aprovada, a instalação da nova Divisão Científica será feita através da nomeação da primeira Diretoria Divisional (Diretor e Vice-Diretor, somente), pela Diretoria da SBQ, ouvidos os proponentes da criação da nova Divisão. O mandato da primeira Diretoria Divisional expirará com o da Diretoria da SBQ na ocasião da sua nomeação.

4. À primeira Diretoria Divisional cabe proceder à instalação da nova Divisão Científica, no máximo até o final do seu mandato, bem como implementar o programa de atividades proposto para a criação da Divisão Científica (item I.1.ii destas Normas). Parágrafo Único: A primeira Assembléia Geral Divisional ordinária deverá definir a composição da Diretoria Divisional (vide item 3ii), com vistas às eleições das próximas diretorias.

\section{Do funcionamento de uma Divisão Científica}

\section{Das finalidades}

Uma Divisão Científica tem por finalidade congregar os sócios da SBQ de uma dada sub-área da Química e realizar atividades que levem à consecução das finalidades da SBQ e a um melhor e maior desenvolvimento da sub-área no País.

\section{Dos sócios}

Uma Divisão Científica congregará sócios da SBQ interessados no desenvolvimento da sub-área da Química por ela abrangida.

Parágrafo Único: Não há limite para o número de divisões científicas a que um sócio pode pertencer. Entretanto, caso um sócio opte por ser membro de mais de duas divisões que não cobram anuidade divisional, a partir da terceira ele pagará uma anuidade extra, por divisão, correspondente a $10 \%$ da anuidade da SBQ.

\section{Da Diretoria Divisional e da Assembléia Geral Divisional}

i) São orgãos da Divisão Científica:

a) a Diretoria Divisional;

b) a Assembléia Geral Divisional.

ii) A Diretoria Divisional será eleita bienalmente pelos sócios efetivos da Divisão Científica, dentre seus pares, e será composta de um Diretor, um Vice-Diretor e, opcionalmente, um Tesoureiro. O mandato da Diretoria Divisional coincidirá com o da Diretoria da SBQ. 
iii) A Assembléia Geral Divisional, órgão soberano da Divisão Científica, será integrada por todos os sócios efetivos quites e reunir-se-á obrigatoriamente bienalmente, em data marcada pela Diretoria Divisional (com quinze dias de antecedência), a fim de julgar o relatório de atividades e a prestação de contas apresentados pela Diretoria Divisional, e em sessão extraordinária convocada pela Diretoria Divisional ou por maioria simples dos sócios efetivos quites com as obrigações com a SBQ.

Parágrafo Único: As convocações extraordinárias da Assembléia Geral Divisional, feitas por meio de cartas individuais quinze dias antes da data fixada, declararão o assunto a deliberar.

iv) A eleição da Diretoria Divisional será feita concomitantemente à eleição da Diretoria e do Conselho Consultivo da SBQ, sendo elegíveis os sócios efetivos quites da Divisão Científica.

a) A eleição será realizada com qualquer número de votantes.

b) A posse da Diretoria Divisional dar-se-á na Assembléia Geral ordinária da SBQ.

Nessa época a Sociedade começava a ter um tamanho apreciável, fruto da dimensão que começaram a tomar suas reuniões anuais (provavelmente em decorrência do acelerado crescimento da pósgraduação em Química no País). Por outro lado, a organização da reunião anual fora da reunião da SBPC começava a dar à SBQ condições estruturais para ampliar sua atuação. Nesse contexto, a diretoria vislumbrou que a organização da RA seria facilitada se compartilhada com colegas de diferentes áreas, organizados em divisões (algo até então não previsto no Estatuto da SBQ). Cabe destacar que, na realidade, algumas ações nessa direção já ocorriam de forma extra-oficial nas divisões de Ensino de Química e de Produtos Naturais.

Cabe destacar que nas disposições transitórias das Normas sobre Divisões Científicas consta que seriam consideradas implantadas todas as divisões que a $16^{\mathrm{a}}$ Assembléia Geral ordinária da SBQ reconhecesse como em funcionamento. No primeiro levantamento foram listadas quatro divisões como implantadas e seis em processo de implantação. Em agosto de 1994, cinco das seis divisões que estavam nessa transição passaram a ser consideradas como implantadas, ficando somente uma delas ainda em andamento (Química de Materiais) e surgindo mais uma para se consolidar (Físico-Química). Novamente esta organização foi acompanhada detalhadamente pelos sócios através das publicações nos Boletins Informativos. No Boletim de agosto de 1994, aparece uma tentativa de organização de uma Divisão de Química de Colóides e Superfícies, a qual infelizmente não se consolidou, mas que deve ser lembrada pelo empenho e trabalho de alguns sócios. A partir de janeiro de 1995, as duas divisões citadas anteriormente como em fase de implantação passam a compor o quadro de ativas, conforme publicado na revista Química Nova de set/ out 1995. Neste mesmo volume também passa a ser listada a Divisão de Catálise, chegando-se a doze divisões. Durante 10 anos essa organização foi mantida e na Assembléia Geral da 29a RA, em 2006, surgiu a Divisão de Alimentos e Bebidas, sendo, portanto a mais jovem divisão da SBQ, totalizando o quadro atual de 13 divisões científicas. Um pequeno histórico de cada uma das divisões foi publicado no suplemento especial de Química Nova (Vol. 25), por ocasião dos 25 anos da $\mathrm{SBQ}^{4}$.

Como está nas normas, o associado efetivo da SBQ tem o direito de inscrever-se em até duas divisões. Se desejar inscrever-se em outras mais, a partir da terceira lhe será cobrada uma taxa de $10 \%$ da anuidade para cada nova divisão. Algumas divisões, por decisão de suas respectivas assembléias, cobram de seus integrantes uma taxa (em torno de $10 \%$ da anuidade) cujos valores são utilizados para a realização de eventos e pagamento de outras despesas. A
Divisão de Ensino de Química cobra 20\%, que corresponde à assinatura anual da revista Química Nova na Escola.

A função de uma divisão científica na SBQ é a congregação de pesquisadores de uma determinada área. A atuação principal é a organização da Reunião Anual através da análise (por assessores $a d$ hoc) dos trabalhos submetidos, a escolha das apresentações orais e dos palestrantes convidados. Ultimamente, muitas divisões têm organizado oficinas no primeiro dia da RA. Outra forma de atuação das divisões é a organização de eventos específicos da sua área, tais como: Brazilian Meeting on Inorganic Chemistry - BMIC (a 13 ${ }^{\mathrm{a}}$ ocorreu em Fortaleza - CE, em setembro de 2006), Brazilian Meeting on Organic Synthesis - BMOS (a $11^{\mathrm{a}}$ ocorreu em Canela - RS, em agosto/setembro de 2005), Encontro Nacional de Química Analíti$c a$ - ENQA (o $13^{\circ}$ ocorreu em Niterói - RJ, em setembro de 2005), Encontro Nacional de Ensino de Química - ENEQ (o $13^{\circ}$ ocorreu em Campinas - SP, em julho de 2006), além de outros. Esses eventos, na maioria com periodicidade de dois anos, congregam pesquisadores nacionais e estrangeiros de alto nível, o que contribui enormemente para o engrandecimento da química brasileira.

\section{PERSPECTIVAS}

A criação e consolidação das regionais e das divisões contribuíram para o amadurecimento da SBQ em vários sentidos: a existência das diretorias das divisões e das regionais diminui a pressão sobre os membros da Diretoria e Conselho Consultivo, facilitando principalmente a organização de eventos e a divulgação das atividades da SBQ em todo o país ${ }^{5,6}$. Com isso a Diretoria e o Conselho Consultivo puderam se dedicar a outras atividades que, nos últimos anos, alavancaram a Sociedade a um patamar de destaque entre as sociedades científicas internacionais. Outro fato importante gerado pela existência das divisões e regionais foi o surgimento de novas lideranças; muitos colegas iniciaram suas atividades nas divisões ou nas regionais e chegaram à Diretoria ou ao Conselho Consultivo com experiência e, assim, puderam contribuir para o engrandecimento da Sociedade.

Qual é o futuro da nossa Sociedade? Como será a SBQ do século 21? A atual estrutura deverá ser mantida?

Essas perguntas são necessárias, pois se observa nos diversos setores da nossa Sociedade uma inquietação quanto à necessidade de uma reformulação no sistema, uma atualização dos seus estatutos e da forma de participação dos associados. Os secretários regionais, como também os diretores de divisão, têm insistido em que há a necessidade de maior autonomia e também maior participação nas decisões da Diretoria e Conselho Consultivo. Cremos que deverá se estabelecer uma forma de permitir uma maior participação das bases nas decisões da Sociedade e uma maior agilidade na execução das atividades e mais facilidade na comunicação da direção com os associados. A implantação da votação eletrônica na última eleição foi uma tentativa de aumentar a participação de todos os associados na eleição, porém o resultado alcançado ainda ficou longe do desejado.

Uma maior participação nas decisões exige em contrapartida uma maior responsabilidade e um comprometimento maior dos associados. As comemorações do trigésimo aniversário da SBQ configuramse como um momento para refletirmos sobre o papel que ela deve ter como sociedade científica e suas responsabilidades para com a construção de uma sociedade mais justa e mais humana, com a preservação dos recursos naturais e ao mesmo tempo com a busca do progresso científico e tecnológico. Dentro desse pensamento, devemos refletir também sobre a nossa responsabilidade particular como membros dessa sociedade e buscar uma maneira de interagirmos mais com os colegas no âmbito da regional ou da divisão. 


\section{REFERÊNCIAS}

1. Peixoto, E. M. A.; Quim. Nova 2004, Ed. Especial, 6.

2. Bechara, E. J. H.; Viertler, H; Quim. Nova 2004, Ed. Especial, 8.

3. Galembeck, F.; Quim. Nova 2004, Ed. Especial, 10.
4. Vieira, P. C.; Barreiro, E. J. L; Quim. Nova 2002, Supl. 1, 5.

5. de Andrade, J. B.; Cadore, S.; Vieira, P. C.; Zucco, C.; Pinto, A. C.; Quim. Nova 2003, 26, 445.

6. Filgueiras, C. A. L.; Quim. Nova 1999, 22, 147. 